Preliminary Report on the Physical Observations Conducted on the National Antarctic Expedition, from 1902 to 1904

Author(s): L. C. Bernacchi

Source: The Geographical Journal, Vol. 26, No. 6 (Dec., 1905), pp. 642-656

Published by: geographicalj

Stable URL: http://www.jstor.org/stable/1776072

Accessed: 27-06-2016 04:46 UTC

Your use of the JSTOR archive indicates your acceptance of the Terms \& Conditions of Use, available at

http://about.jstor.org/terms

JSTOR is a not-for-profit service that helps scholars, researchers, and students discover, use, and build upon a wide range of content in a trusted digital archive. We use information technology and tools to increase productivity and facilitate new forms of scholarship. For more information about JSTOR, please contact support@jstor.org.

The Royal Geographical Society (with the Institute of British Geographers), Wiley are collaborating with JSTOR to digitize, preserve and extend access to The Geographical Journal 


\title{
PRELIMINARY REPORT ON THE PHYSICAL OBSERVATIONS CONDUCTED ON THE NATIONAL ANTARCTIC EXPEDI- TION, FROM 1902 TO 1904.*
}

\author{
By L. C. BERNACCHI, F.R.G.S.
}

ONE of the principal scientific objects of the National Antarctic Expedition was a magnetic survey of the south polar regions of the globe.

The magnetic survey of 1843 1849, conducted at sea under Sir James Ross, with fixed observatories established at Toronto, St. Helena, Capetown, and Hobart, formed one of the most valuable contributions to our knowledge of terrestrial magnetism, and enabled Sabine to construct maps of equal lines of magnetic declination, inclination, and intensity for the whole world, for the completion of which every available observation made up to 1870 was employed. From 1870 to 1880 was a period of activity in magnetic observations on sea and land, and the magnetic charts published in the report of the scientific results of H.M.S. Challenger give a fairly accurate representation of the normal distribution of the Earth's magnetism between parallels $70^{\circ} \mathrm{N}$. and $40^{\circ} \mathrm{S}$. for the epoch 1880 ; but beyond these limits there is a considerable degree of uncertainty, especially in the southern regions south of $50^{\circ} \mathrm{S}$., where we have very few observations since 184.5 , and where the changes in the magnetic elements during the last sixty years have been considerable.

Of recent years elaborate magnetic surveys have been conducted in various parts of the world, and with splendid results, but it has proved almost impossible to establish and maintain a theory of terrestrial magnetism unless observations in the Antarctic Regions were carried out. All calculations, however excellent, must necessarily fail if that gap in our information is lacking; thus the completion of the theory of the Earth's magnetism remained an unsolved problem. The necessity of a survey of the magnetic constants, changes, etc., within the Antarctic circle therefore became essential in its importance with regard to the advancement of our knowledge of terrestrial magnetism. Whether the magnetic observations of the Discovery, taken in a high southern latitude, when combined with observations of other expeditions and land stations will materially advance our knowledge remains to be seen; certainly they cannot fail to throw considerable light on the magnetic conditions of the Antarctic Regions.

In this preliminary paper no attempt has been made to give results, but only to give some indication of the magnetic and other physical work carried out, more especially while the Discovery was frozen in from February, 1902, until February, 1904. An attempt to deal with so large a mass of observations both on land and sea at this early date would only lead to confusion, and therefore conclusions here put forward must be accepted with considerable reserve.

Besides the Fox and Lloyd-Creak instruments for the determination of inclination and total force at sea, the Discovery was supplied with unifilar magnetometers and barrow-circles for the determination of absolute declination, horizontal force, and inclination on shore, and with a set of Eschenhagen variometers or self-recording

* Research Department, May 8, 1905. Mr. Bernacchi said: I should like, before I read this paper this afternoon, to ask you to understand that the paper was written some months ago, before any attempt was made to reduce the physical work of the Discovery. Therefore any results put forward in the paper must necessarily be accepted with considerable reserve. Some of the observations, I understand, have already been reduced, but I have not had access to the results, therefore I cannot put any definite results before you this afternoon. 
instruments for obtaining a continuous photographic record of the changes in declination, horizontal force, and vertical force.

Some time previous to the departure of the British and German expeditions, a scheme of international co-operation in magnetic work was established, and besides the continuous observations with the variometers, regular term days and term hours were agreed upon for obtaining special observations with them at the same moment of Greenwich mean time.

The southern stations co-operating were New Zealand, Melbourne, and Mauritius. The Argentine Government sent a party to Staten island, near Cape Horn, and Germany one to Kerguelen island ; in the northern hemisphere, Kew, Falmouth, Bombay, and German and other foreign observations. The magnetic observatory at Christchurch, New Zealand, was made the primary base station of the expedition in the southern hemisphere, and here the constants for our instruments were determined before sailing in 1901, and again on returning in 1904. Our thanks are due to the New Zealand Government for their courtesy in placing the observatory at our disposal, and to Dr. Coleridge Farr and Mr. H. F. Skey, of the observatory, for their valuable assistance.

With the sea observations it is not our purpose to deal in this paper, but exclusively with the physical work conducted from February, 1902, to February, 1904 , on shore.

As soon as a suitable winter spot was found for the Discovery, a site was selected for the magnetic observatory. From a magnetic point of view, an observatory of this kind should be placed in a position where conditions are not disturbed by the presence of magnetic rocks; but it would be difficult, if not impossible, in the whole length of Victoria Land to find such an undisturbed locality, unless it were on the surface and near the edge of one of the extensive ice-flows far from the actual coast-line, such as the Great Ice Barrier or the iceflow in the vicinity of Lady Newnes bay.

The spot selected for the observatory (lat. $77^{\circ} 50^{\prime} 50^{\prime \prime}$ S., long. $11^{\mathrm{h}} 7^{\mathrm{m}} 0^{\mathrm{s}}$ E.), although the best available, was hardly an ideal one for magnetic observations. It was on the extremity of a peninsula extending in a south-west direction from the base of an island formed by Mounts Erebus and Terror. Length about 10 miles, and breadth 1 mile, and average height about 800 feet. The extreme end, however, where the observatory was placed was only between 30 feet and 50 feet above sea-level. The geological formation is of a volcanic nature, principally basalt, and, as will be seen later, had considerable influence on the absolute values of H.F., V.F., and inclination. As soon as the Discovery reached her winter quarters (a small inlet to the south of the end of the peninsula), the observational huts were immediately landed, and erection commenced. These huts were constructed of large asbestos slates, screwed on to the outside and inside of a wooden framework. The larger of the two, used for the variation house, was $11.6 \mathrm{fcet}$ by 11.6 feet, and 6.8 feet in height. The absolute house was slightly smaller.

Although, perhaps, small log huts would have been more suitable, they certainly would not have been so light, compact, and easily portable. The asbestos huts were, on a whole, fairly satisfactory, but had some grave disadvantages.

By the end of February, 1902, the erection of the variation house (A) was completed, and the variometer set up and working for the term day, March 1st. The absolute house (B) was completed later, and placed 25 yards to the north of (A). Both huts were 30 feet above sea-level. For the absolute instruments a brick pillar was built up through the floor of B, 3 feet 6 inches above it, and 2 feet by 1 foot 6 inches square. The door of the hut faced nearly due west, and narrow openings were made across the roof and down the north and south walls in, as near 


\section{PRELIMINARY REPORT ON THE PHYSICAL OBSERVATIONS CONDUCTED}

as possible, the geographical meridian, for the purpose of using a transit instrument or theodolite. An azimuth peg was erected a little to the south of west, 30 yards from the observational pillar. The peg was an iron one, driven into the frozen ground to a considerable depth, and only 1 foot showing above the surface. At the top was a circular hole, across which a wire was stretched and a light placed behind when bearings were taken from the hut in the dark winter months.

For the variometers in A, a bench was erected in the magnetic meridian, 8 feet 5 inches in length and 1 foot 6 inches in breadth, supported at one end by a drain pipe 1 foot 6 inches diameter sunk into the frozen ground, and at the other extremity a thick pillar of wood sunk in the same way. The thickness of the wood slab forming the bench was 3 inches, and was 2 feet 9 inches above the ground.

The latitude of the observatory is the mean of a large number of meridian and circum-meridian altitudes of the sun, taken during the summers of 1902-1903 and 1903-1904 with theodolite and sextant. Until all these observations have been re-worked and checked it is probably a few seconds in error. The longitude is that derived from a few occultations of stars by the moon, and until re-worked is, probably, also slightly in error.

The azimuth of the fixed mark for declination observations was first determined by theodolite in May, 1902, and subsequently by a number of sun azimuths in the spring and summer of 1902-1903 and 1903-1904, using the azimuth mirror of the magnetometer and finding the mean time at place by altitudes of the sun in a mercury horizon.

As soon as possible the absolute values of declination, horizontal force, and inclination were determined, the instruments employed throughout the two years being the same, viz. unifilar magnetometer No. 25 by Elliott, and inclinometer No. 27 by Barrow. All the magnets were adjusted in their stirrups for the latitude, and during the first two months magnet $25 \mathrm{D}$ was employed in determining the horizontal force, but as the value of $P$. for this magnet was found to be normally negative, this was changed for $25 \mathrm{~A}$, which was subsequently used throughout.

The method of observation was the same as that employed at Kew and other observatories, the only difference being that, instead of distances 30 and $40 \mathrm{cms}$. in the deflection experiment, 42 and $56 \mathrm{cms}$. were used, owing to the small size of the force. The approximate value of the declination was found to be $152^{\circ} \mathrm{E}$., H.F., 0.06 C.G.S. unit, and dip $-84^{\circ} 40^{\prime}$. The reduction and publication of the absolute observations has been undertaken by the Hydrographic Department of the Admiralty.

The changes in the values, especially declination and horizontal force, are so rapid and irregular that little can be gathered from individual observations. It is only by examining the main position of the curves on the magnetograms from month to month that the changes can be clearly detected. However, I think it will be found, when these observations are published, that there is an indication of a large annual variation in all the elements. This, we shall see later, is more clearly indicated on the magnetograms.

The declination reaches a maximum easterly value towards the time of the autumnal equinox (September), or a little later, and a minimum near the vernal equinox (March), the annual range being about $2^{\circ}$. The horizontal force increases towards the autumnal equinox, and decreases towards the vernal, the range being approximately, 0.001 C.G.S.; while the dip decreases towards the autumnal and increases towards the vernal equinox, the range in 1903 being nearly $30^{\prime}$.

Magnetically disturbed days, especially in the summer, were very frequent. It was only on a few days in each month that good absolute observations were 
possible. It was not always easy to select quiet days. Frequently attempts at absolute observations had to be abandoned on account of too great disturbance, and, in the winter, sometimes on account of a blizzard, which made intercourse between the ship and the shore, and observing in the small exposed absolute house, almost impossible. In November, 1903, a large tent was erected on the unbroken sea ice in McMurdo strait, 2 miles from the nearest shore-line, and over a spot where the depth of water was 220 fathoms. Three sets of observations were taken, viz. on November 4, 6, and 8, with an interval of two days between each set. The variometers were running simultaneously. The results obtained were rather surprising. The following table shows the results of the observations of November 8 compared with those taken on shore on November 2 :-

TTABLE I.

\begin{tabular}{c|c|c|c|c}
\hline Date. & Horizontal force. & Total force. & Vertical force. & Inclination. \\
\hline Nov. 2, on shore & 0.06929 & C.G.S. & C.G.S. & 0 \\
Nov. 8, on ice ... & 0.04367 & 0.7306 & 0.7273 & 84336 \\
Differences ... & 0.02562 & 0.6982 & 0.6968 & 86248 \\
\hline
\end{tabular}

From the mean of all three sets a correction can be found to apply to the observations taken on shore. Unfortunately, at this time persistent overcast weather prevailed, and no observations of declination were possible on account of there being no sun visible for the determination of a true bearing. This was not done until January 30,1904 , and was then found to be $152^{\circ} 43^{\prime} 52^{\prime \prime} \mathrm{E}$. at $3^{\mathrm{h}} 39^{\mathrm{m}}$ p.m. local mean time, the declination on shore for that time, taken from the magnetograms of January, being about $152^{\circ} 40^{\prime} \mathrm{E}$. Thus the declination seems little affected by the magnetic character of the rocks.

The establishment of the absolute house out on the sea ice, although, perhaps, possible during the second year, would have been attended by considerable difficulty and some risk, especially as it would have been fully exposed to the heavy winter storms, and the surface of the ice, being hard and smooth, offered very little holding ground. During the first year practically nothing was known of the ice-conditions in the strait; indeed, up to quite late in the year the ice within a few hundred yards of the ship was continually breaking up and drifting away.

The tent on the ice was made the base station for the observations taken on the Ice Barrier sledge journey of November 10 to December 10, 1903, with inclinometer No. 27 by Barrow, having two reversible inclination needles and two totalforce needles.

The objects of the Ice Barrier sledge-journey were to determine the extent of the ice-sheet which is terminated by the Great Ice Barrier in a direction due southeast from Mount Erebus; to ascertain, if possible, whether land existed in that direction; to take a series of magnetic observations where they would probably not be disturbed by magnetic rock masses; to investigate the surface of the barrier in detail, and the meteorological conditions prevailing over this ice-sheet during the summer months.

The farthest point reached was about 155 geographical miles south-east of Mount Erebus, the total distance traversed being about 340 statute miles. Constant southwest winds with drifting snow were experienced. The geographical positiong of the "camps" were determined, whenever possible, by means of sextant observations of the sun in an artificial mercury horizon. 
With the exception of those taken on November 28, all magnetic observations were taken in the evenings between 7 p.m. and 9 p.m. after the day's march. On two occasions only was it possible to observe in the open air. In most cases the strong cold wind with drifting snow prevented open-air observations, and they were then taken in the small, low sleeping-tent while the other two occupants waited outside. The following are some of the results obtained :-

TABLE II.

\begin{tabular}{|c|c|c|c|c|c|c|}
\hline Date. & & Camp. & Latitude. & Longitude. & $\begin{array}{l}\text { Inclination. } \\
\text { Mean } 2 \text { needles. }\end{array}$ & Total force \\
\hline $\begin{array}{c}\text { November } \\
\text { " } \\
\Rightarrow \\
" \\
" \\
"\end{array}$ & $\begin{array}{r}8 \\
14 \\
17 \\
20 \\
23 \\
26 \\
28\end{array}$ & $\begin{array}{l}\text { Base } \\
\mathbf{E} \\
\mathbf{H} \\
\mathbf{M} \\
\mathbf{P} \\
\mathbf{S} \\
\mathbf{W}\end{array}$ & $\begin{array}{ccc}0 & \prime & \prime \prime \\
77 & 50 & 50 \\
78 & 6 & 0 \\
78 & 33 & 0 \\
78 & 50 & 0 \\
28 & 5 & \text { geo. miles } \\
50 \cdot 0 & \text { geo. miles } \\
79 & 33 & 0\end{array}$ & $\begin{array}{cccc}\text { h. } & \mathrm{m} . & \mathrm{s} . \\
11 & 7 & 0 & \mathrm{E} . \\
168 & 26 & 0 & \mathrm{E} . \\
170 & 2.2 & 0 \\
172 & 1 & 30 \\
\text { S.E. of } \mathrm{M} \\
\text { S.E. of } \mathrm{M} \\
175 & 55 & 30\end{array}$ & \begin{tabular}{rrr}
0 & \multicolumn{1}{c}{$l$} & \multicolumn{1}{c}{} \\
-86 & 24 & 84 \\
-86 & 0 & 0 \\
-85 & 45 & 39 \\
-85 & 27 & 70 \\
-85 & 4 & 22 \\
-84 & 58 & 83 \\
-84 & 49 & 31
\end{tabular} & $\begin{array}{c}\text { C.G.S. } \\
0.6982 \\
0.6694 \\
0.6487 \\
0.6166 \\
0.6031 \\
0.5881 \\
0.5855\end{array}$ \\
\hline
\end{tabular}

The above observations are very uniform, and with the exception of an observation taken on the return journey close under a small volcanic island called "White Island," which has been rejected on account of showing slight disturbance, they do not seem to be at all influenced by land-masses. The decrease in the inclination over 155 geo. miles is $1^{\circ} 35^{\prime} 53^{\prime \prime}$, or about $1^{\prime}$ for each $1 \cdot 6$ geo. mile. The total change in the total force amounts to 0.1127 C.G.S. units. The total force has been found by the formula given in the Admiralty 'Manual of Scientific Enquiry.'

These observations ought to give a capital idea of the rate of change over an apparently undisturbed area in these latitudes, and may be of some assistance in more accurately locating the position of the south magnetic pole. Besides observations for inclination and total force, the declination was observed by means of a prismatic compass, but these have not yet been worked out excepting very roughly while on the march.

Declinations were also observed by Captain Scott on his southern and western sledge-journeys, and ought to prove of considerable value. On the western journey the isogonic of $180^{\circ}$ was crossed in about lat. $77^{\circ} 50^{\prime}$ S., long. $155^{\circ}$. E. during the months of November and December, 1903.

The self-recording variometers supplied to the expedition were the delicate transportable type devised by the late Prof. von Eschenhagen, and made by the firm of $\mathrm{O}$. Toepfer, of Potsdam. They consist of a declinometer, a horizontal and a vertical force magnetometer, and self-recording apparatus. These instruments, especially the first-named two, possess several advantages over the instruments used hitherto, but are almost too fragile and sensitive for use at a polar station.

The magnets for the declinometer and H.F. instruments consist of wellhardened laminar pieces of watch-spring steel, $25 \mathrm{~mm}$. in length and weighing about 1.5 gramme. A light aluminium frame supports the mirror and the magnet, and this is hung by means of a double hook on a small cross-piece attached to the bottom of a quartz fibre suspension. The declinometer gave entire satisfaction throughout the two years. Unfortunately, the quartz fibres supplied for the horizontal force instrument, instead of being about $\frac{1}{10}$ to $\frac{1}{20} \mathrm{~mm}$. thick, were very much finer, being galvanometer fibres, and therefore made the magnet more sensitive than was desirable or convenient. 
The vertical force instrument was a modification of the Lloyd balance, and as it was only just completed before leaving England, very little was known of its behaviour even at Potsdam. This instrument was a source of constant trouble. The needle was balanced for a dip of about $70^{\circ} \mathrm{N}$. The magnetic dip at Winter harbour being about $84^{\circ} \mathrm{S}$., the pull on the south end of the needle could not be overcome by the small weights and magnets supplied for the purpose, and therefore additional weights had to be added to the north end, which increased the temperature coefficient of the balance.

The principal advantage of the recording apparatus is that all three elements, base lines, and a temperature curve are on the same photogram for the day. In the summer-time, however, when the movements of the magnets are large and frequently highly disturbed, this leads to confusion.

The following is the arrangement of the instruments in the magnetic meridian: North extremity, the recording cylinder; at about $120 \mathrm{cms}$. from the cylinder, the declinometer; then the H.F. instrument at about $165 \mathrm{cms}$., and at the south extremity the V.F. instrument.

During the first year the walls of the variation house were banked with snow, and a large brass heating lamp kept burning within, so as to maintain as uniform temperature as possible. This lamp was frequently a source of danger and inconvenience of a most aggravating nature, and required constant watching; nor was it successful in keeping a uniform temperature, and giving out a fair proportion of heat for the amount of oil burned. It was altogether an unsuitable type. During the second year the house was entirely buried under snow, and although at times the temperature within was very low, viz. $-30^{\circ}$ Fahr., it remained fairly uniform from month to month.

From May, 1902, until January, 1904, the deciinometer was never interfered with, nor its zero mirror altered.

During the first year the H.F. instrument was two or three times found to be out of adjustment and altered, but remained untouched during the second year, while the V.F. instrument was altered from time to time during both years.

The following are approximately the scale values employed, equal to $1 \mathrm{~mm}$. of the ordinates of the curves:-

$$
\begin{aligned}
& \mathrm{D}=1^{\prime} \cdot 4 \text { per millimetre. } \\
& \mathrm{H}=0.000015 \text { dyne per millimetre. } \\
& \mathrm{V}=0.00016 \text { dyne per millimetre. }
\end{aligned}
$$

$\mathrm{V}$ is about the sensitiveness recommended in the international programme, but $\mathrm{H}$ is much more sensitive. The sensitiveness of $\mathrm{V}$ remained fairly constant throughout, excepting once or twice when, for a short time, it was purposely made more sensitive. It remained fairly constant during the second year, but altered a few times during the first.

The method of determining the sensitiveness was by deflecting the magnets with one of the unifilar collimating magnets at certain known distances, and then carefully finding the moment of the deflecting magnet by a set of absolute observations. If $\mathrm{M}$ be the moment of the magnet deflecting, $d$ the distance employed, and $\mathrm{E}$ the amount of deflection, then the sensitiveness is found as follows :-

$$
\left[\frac{2 \mathrm{M}}{\left(d^{2}+\mathrm{E}^{2}\right)^{\frac{3}{2}}}\right]
$$

The only method employed for determining the temperature coefficient of the magnets was by taking sets of absolute observations while the temperature in the variation house was comparatively high, then allowing the temperature to fall 
rapidly and taking another set of absolute values; but as the movements of the magnets are so large and rapid, this method is not altogether satisfactory, and perhaps the best method is to compare the curves on days when the temperature is high with those when the temperature is low.

The determination of the temperature coefficient for $\mathrm{V}$ by this method should present no difficulty, but for $\mathrm{H}$ it will not be so easy, as the coefficient for this short, light magnet is so small.

Prof. Eschenhagen gives the temperature coefficient for one of his uncompensated variometers as amounting to $7 \gamma$ for $1^{\circ} \mathrm{C}$.

During the first year the curves are much finer and sharper than during the second, on account of a more sensitive bromide paper being employed, and consequently a smaller light slit. The magnetograms were usually developed once a week by means of ortol-soda developer, which has the advantage of being exceptionally clean to use, and giving rich dark tones to the curves.

On the international term days (1st and 15th of each month) the recording cylinder was run at high speed with a very wide time scale, viz. $48 \mathrm{cms}$. in two hours. The high speed was continued for about half the term day, the other half being the usual slow run, or $48 \mathrm{cms}$. in twenty-four hours.

'Towards the end of the second year the supply of recording paper became very short, and from the end of September had to be distributed equally over the following months, amounting to about a week in each month. This is the only serious break in the two years' record. In all there are records for about six hundred days.

On casually looking through all the records, the first thing to impress one is the extreme disturbed nature of the curves. On only a few days of the year, and these almost entirely during the winter, do they really deserve the name of quiet. Secondly, the large diurnal variation in the spring and summer months. Thirdly, the conspicuous difference of the mean distance of the curves from their base lines from month to montb, or, in other words, the annual variation.

The movements of the magnets, especially in summer, are so sudden and large, being in the form of peaks and bollows, as at times to move well beyond the range of the recording cylinder, and therefore on very disturbed days considerable portions of the curves are lost.

It will be seen, on examining the records, that some of these sudden movements, especially in the H.F., occur at approximately the same time on a number of consecutive days without any apparent cause. Generally speaking, a large movement of this kind will take place nearly simultaneously in all three curves, but sometimes only in one, with little or no indication of it in the others.

On returning to New Zealand, a rough comparison between one or two of our records was made with those of Christchurch observatory, and it was clearly seen, especially on the records of June 28, 1903, that some of the larger peaks and hollows were almost simultaneously produced at Christchurch, but to a much smaller extent. Whether the direction of the disturbances was the same we did not examine. Some of the most disturbed days at Christchurch and at Kew are also some of our most disturbed ones, such as April 10, 1902, and November 1, 1903, which appears to have been a disturbed day over a large portion of the globe.

The following were some of the most disturbed days during the year 1902 :-

$$
\begin{aligned}
& \text { March } 16,17 .^{*} \\
& \text { April } 9, \dagger 10, * \dagger 11,+20 \text {. } \\
& \text { May } 8,9, \dagger 10 . \dagger \\
& \text { June } 1, \dagger 26,27,29 \text {. } \\
& \text { July } 8, \dagger 24,25 \text {. }
\end{aligned}
$$$$
\text { * Very disturbed days. }
$$

August 21, 22, 24.

September 2, 20, 23 .

October $22,29,30,31 . *$

November $13,14,15,16,17,18$. 
The curves for December of both years, and for January and February, are so confused and disturbed that it is quite impossible to tell an unusually disturbed day from a moderately quiet one. Measurements of the curves for December and January especially will present many difficulties, the movements are so rapid, have crossed and re-crossed so frequently, and in many cases are lost, being beyond the range of the recording cylinder.

A careful record of all the auroræ seen during 1902-1903, has been kept, but a comparison between the times of auroræ displays and the curves for the same time has not been made, excepting in a very cursory manner. Although aurora were observed on some disturbed magnetic days, there were days when curves were not abnormally disturbed when compared with curves on days when no aurora was seen.

On July 3 and 4, 1902, a comparatively bright and extensive aurora, which continued for a number of hours, was observed, but the curves for those hours are less disturbed than usual. There is, however, some indication of a sudden large disturbance, especially in the H.F., a little before the commencement of an aurora display, but this may be a mere coincidence.

The following tables give a very approximate idea, for the year 1903, of the mean diurnal variation for each month, with the mean times of maximum and minimum, also the change of the mean position of the curve from its zero from month to month, or, in other words, what appears to be the amount of annual variation. Only values for declination and horizontal force are here given, and are obtained from the four quietest days in each month. The values for November, December, and January are only partly given; the curves are much too disturbed to obtain approximate values from a few measurements. The determination of even approximate values of vertical force would involve considerable labour, as the base values have been so frequently altered and the temperature coefficient is so large.

TABLE III.

\begin{tabular}{|c|c|c|c|c|c|c|c|c|c|}
\hline \multicolumn{4}{|c|}{ Month, 1903.} & $\begin{array}{l}\text { Mean } \\
\text { daily } \\
\text { range. }\end{array}$ & $\begin{array}{c}\text { Mean } \\
\text { time of } \\
\text { maximum. }\end{array}$ & $\begin{array}{c}\text { Mean } \\
\text { timse of } \\
\text { minimum. }\end{array}$ & $\begin{array}{c}\begin{array}{c}\text { Horizontal } \\
\text { force in } \\
\text { C.G.S. units. }\end{array} \\
0.00085\end{array}$ & $\begin{array}{c}\text { Mean } \\
\text { time of } \\
\text { maximum. }\end{array}$ & $\begin{array}{c}\text { Mean } \\
\text { time of } \\
\text { minimum. }\end{array}$ \\
\hline $\begin{array}{l}\text { February } \\
\text { March } \\
\text { April } \\
\text { May } \\
\text { June } \\
\text { July } \\
\text { August } \\
\text { September } \\
\text { October } \\
\text { November } \\
\text { December. }\end{array}$ & $\begin{array}{l}\ldots \\
\ldots \\
\cdots \\
\cdots \\
\cdots \\
\cdots \\
\cdots \\
\cdots \\
\cdots\end{array}$ & $\begin{array}{l}\cdots \\
\cdots \\
\cdots \\
\cdots \\
\cdots \\
\cdots \\
\cdots \\
\cdots \\
\cdots \\
\cdots \\
\cdots\end{array}$ & $\begin{array}{l}\ldots \\
\cdots \\
\cdots \\
\cdots \\
\cdots \\
\cdots \\
\cdots \\
\cdots \\
\cdots \\
\cdots \\
\cdots\end{array}$ & $\begin{array}{lr}1 & 23 \\
0 & 58 \\
0 & 36 \\
0 & 30 \\
0 & 22 \\
0 & 38 \\
0 & 48 \\
1 & 30 \\
2 & 8 \\
1 & 42 \\
1 & 27\end{array}$ & 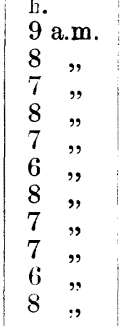 & $\begin{array}{ll} & \text { h. } \\
7 & \text { p.m. } \\
6 & , \\
7 & \prime \\
7 & , \\
6 & , \\
4 & , \\
4 & , \\
5 & , \\
7 & , \\
5 & , \\
5 & ,\end{array}$ & $\begin{array}{l}0 \cdot 00085 \\
0 \cdot 00061 \\
0 \cdot 00038 \\
0 \cdot 00033 \\
0 \cdot 00020 \\
0 \cdot 00038 \\
0 \cdot 00040 \\
0 \cdot 00074 \\
0 \cdot 00093\end{array}$ & 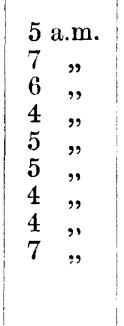 & $\begin{array}{l}4 \\
4 . \mathrm{p} . \\
2 \quad, \\
3 \quad, \\
4 \quad, \\
3 \quad, \\
3 \quad, \\
3 \quad, \\
3 \quad, \\
2 \quad,\end{array}$ \\
\hline
\end{tabular}

Table IV.

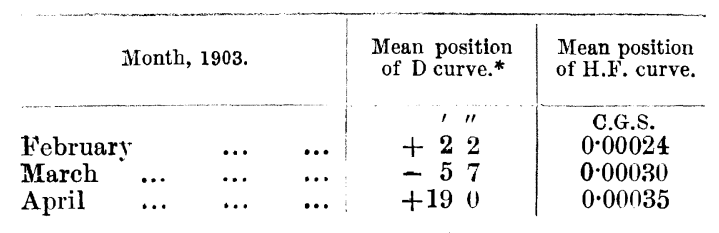

* By mean position, of course, is meant its mean distance from its base line given in its own scale value. 


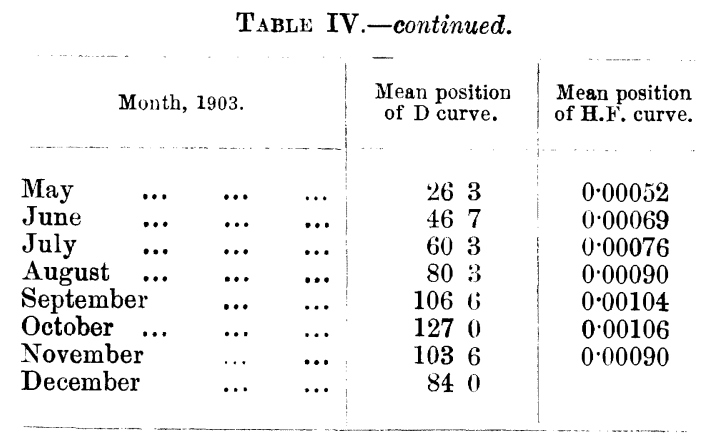

An examination of the above tables shows that the diurnal variation in declination attains a maximum towards the end of September or beginning of October, being then over $2^{\circ}$, and then gradually decreases, until at about midwinter (June) it is a minimum, being then only $22^{\prime}$. However, the two values given for November and December are very approximate, and when all the curves for these respective months have been measured, the daily range may prove to be somewhat greater. The daily maximum and minimum occurred approximately at the same time in each month-that is, within two or three hours-the mean time of maximum declination being about 8 a.m., and of minimum about 6 p.m.

The annual variation shown in Table IV. is about $2^{\circ}$, the minimum value being in March and the maximum in October. The total annual range in horizontal force is about 0.001 C.G.S. unit, the maximum being in October and the minimum about February.

The largest diurnal range in H.F. is in October, or perhaps a little later, and the smallest in June. The times of maximum and minimum are about three hours earlier than in the case of the declination, being about 5 a.m. for maximum and 3 p.m. for minimum.

At present nothing can be said definitely with regard to the secular change. There is some sign of a secular increase in declination and horizontal force and decrease in inclination, but to what extent it is impossible to tell until the whole of the two years' record has been reduced.

There are many problems of deep interest in connection with these photographic records, but which it is impossible to even attempt to deal with here. Such, for instance, are the minute and regular magnetic waves or oscillations clearly shown on some of the H.F. curves obtained on term days from the high-speed cylinder. Some of these waves are very sharp and well defined, and have a period of about eight secunds. Whether these small movements occur simultaneously at New Zealand and more northern stations it will be interesting to compare. On September 21, 1903, there was a partial eclipse of the sun at Winter harbour. The times of contact and position, angles and magnitude, were carefully calculated, and an observational programme prepared. The time of eclipse was from $3^{\mathrm{h}} 40^{\mathrm{m}}$ p.m. M.T. to 5.37 p.m.--duration $1^{\mathrm{h}} 57^{\mathrm{m}} 14^{\mathrm{s}}$, and magnitude 0.94 . Unfortunately, thick, overcast weather prevailed during the afternoon, and not a glimpse of the sun was seen. During the time of the eclipse a high speed record was obtained on the magnetograph. Whether a magnetic effect referable to the eclipse will reveal itself remains to be seen.

The only other magnetic observations on land that remain to be mentioned are a set of dips and total force taken at Cape Adare in January, 1902, and again in 1904, and a set of dips and total force at Cape Crozier in January, 1902. The 
values obtained at Cape Adare are practically the same as obtained in 1899, and show little sign of secular change. The observations at Cape Crozier are largely effected by the magnetic character of the rocks. During February of 1904 the Discovery endeavoured to penetrate into Wood bay for the purpose of getting magnetic observations on shore, or on fast ice removed from the shore at the bottom of the bay and as close to the magnetic pole as possible, but the attempt had to be abandoned on account of the bay being packed with heavy close ice.

During the year 1900 a set of magnetic observations were taken on shore in Wood bay by the Southern Cross Expedition, and gave an inclination of $88^{\circ} 2^{\prime}$, but as the volcanic character of the rock there is much similar to that at Winter Quarters, it is possible that this value is too small, and that Wood bay is closer to the magnetic pole than this would indicate-probably as much as $88^{\circ} 53^{\prime}$ in December and $89^{\circ}$ in February. The observations taken on board the Discovery in Wood bay, when reduced, may throw some light upon this matter.

A sledge journey from Wood bay in the direction of the magnetic pole may be attended by considerable difficulties on account of the lofty mountain ranges that may have to be crossed, but at Lady Newnes bay, about a degree further north, the mountains are comparatively low, and entirely snow-clad. A journey to the magnetic pole from here might be successful, especially during the summer months of December, January, and February, when the temperatures are such as permit the handling of magnetic instruments without undue inconvenience.

\section{Auroral Observations.}

A record of the auroræ visible during the two winters 1902-1903 was kept. The observations were generally made by the officer who was on meteorological duty for the night-a duty in which all the members of the Discovery's wardroom participated.

Ordinarily, the observations consisted of noting the time, position of the auroræ, both altitude and amplitude, its intensity, form, movement, and duration. These observations were entered in a special journal kept for the purpose, and a chart of the surrounding bills was supplied each night for drawing in its position with regard to the magnetic meridian, etc. Whenever the display was fairly extensive, the physicist was called and special observations taken, such as photometric measurements of its intensity, spectroscopic, atmospheric electricity and width of bands, altitudes, and times of special movements.

On a whole the displays, although very frequent, were extremely poor, and were generally in the following forms:-

1. Faint lights, with no defined forms.

2. Luminous patches which frequently presented the appearance of clouds.

3. Incomplete arches or segments of arcs, of which the brilliancy was nut uniform nor the border regular. From these arches rays would frequently shoot up intermittently.

4. Rays or vertical shafts separated from each other at a greater or less distance.

5. In one or two exceptional cases irregular bands formed of rays or vertical shafts pressed close together and forming "draped auroræ."

The faint lights and luminous patches were of the most varied dimensions, sometimes very small, and at other times occupying almost the whole of the eastern sky. Their brilliancy was rarely much more intense than that of stars of the 4th magnitude, or even the Milky Way. They formed as if it were a white veil over the sky, through which stars of small magnitude were plainly visible. A 
clearly defined arch, formed of a homogeneous luminous mass touching the horizon at both extremities, was rarely seen.

From the middle of the moon's first quarter to the middle of its last quarter the auroræ were generally quite invisible. Spectroscopic observations of the auroræ were not successful, due, apparently, to the weak intensity of the light. On some occasions the characteristic yellow line near $\mathrm{D}$ was seen by means of a direct-vision spectroscope, but although plates were exposed night after night in the prismatic camera, the times of exposure varying all the way from a few minutes to twenty-four hours or more, not the slightest trace of the spectrum could be discovered on developing the plates. The spectrum plates (Cadet) appeared to be in fairly good condition, good photographs of the spectrum of Kryptom gas, and of the sun and atmosphere having been obtained on them.

The observations of atmospheric electricity taken during the displays reveal no special effect referable to the aurora.

The following tables give (1) the number of days in each month when auroræ were recorded ; $(2)$ the daily period of the aurora, with its mean altitude.

\section{TABLI: V.}

\begin{tabular}{|c|cc|ccccc|c|c}
\hline Year. & March. & April. & May. & June. & July. & August. & September. & Total. \\
& & & & & & & & & - \\
1902 & - & 10 & 8 & 14 & 11 & 10 & 3 & 56 \\
1903 & 2 & 19 & 14 & 16 & 17 & 14 & 2 & 84 \\
\hline Days & 2 & 29 & 22 & 30 & 28 & 24 & 5 & 140
\end{tabular}

'Table VI.

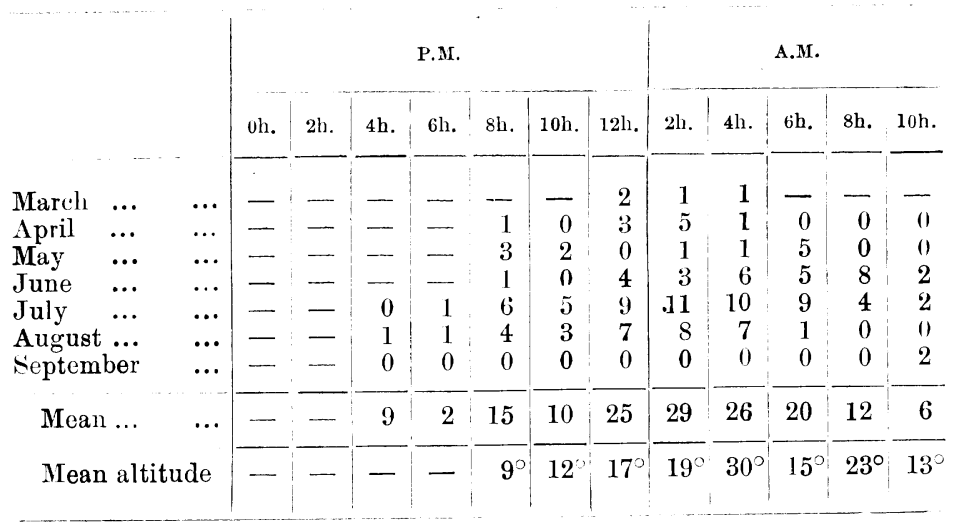

An examination of the above tables show (1) that the largest number of auroræ occur during the winter months, June and July, and that there is some indication of May being relatively a quiet aurora month in both years ; but this may be purely an accident. The small number observed in March and September is, of course, due to the large amount of daylight. Although Table VI. is not strictly accurate, only the observations of one year having been used, the daily variation of the aurora at Winter harbour is clearly shown, the maximum occurring at about 2 a.m., which is also about the time of the mean maximum altitude of the display. The time of maximum appears to depend upon the latitude, it being later as we go towards 
the pole. Thus at Cape Adare $\left(71^{\circ} \mathrm{S}\right.$.) it is about 9 p.m., and on the Belgica Expedition $\left(71^{\circ}\right.$ S.) also about 9 p.m. The aurora with us usually appeared first at about 4 p.m., low down on the horizon, and gradually moved up towards the zenitb, reaching a maximum at about 4 a.m.

There are many points of interest, such as the intensity periods, the monthly period due to the moon's phases-the magnetic direction of auroræ at different hours of the day-simultaneous appearance of auroræ with those at northern stations, and with sudden outbreaks of solar spots; its relation with terrestrial magnetism and meteorological phenomena, etc.

With regard to the direction of auroræ at Winter harbour, it is interesting to note that displays were almost exclusively confined to the eastern sky, which was also the direction from which the prevailing winds blew. Auroræ were seldom seen in the west. Arches and segments of arcs at right angles to the magnetic meridian (N.) were frequently recorded.

A number of observations have been made by Antarctic expeditions since 1897, and when all these have been published and tabulated, some light may be thrown upon the geographical distribution of the aurora in the southern hemisphere.

\section{Seismic Observations.}

The Milne seismograph supplied to the expedition was erected at Winter harbour in the variation house during March, 1902. This instrument (No. 37) was made by R. W. Munro, London, of non-magnetic materials. The drain-pipe upon which the bed-plate was lightly fixed was 1 foot 6 inches in diameter, and was sunk down through a thin layer of ice until it rested upon a solid bed of frozen earth and stones. The height of the pipe above the ground was $19 \frac{1}{2}$ inches. When the column had been made rigid, with bed plate attached, the instrument was set up in the geographical meridian, the aluminium boom being N.-S., and the balance weight and attachment of tie at the regulation distance from the pivot, viz. $7 \mathrm{~mm}$. and $125 \mathrm{~mm}$. respectively. By means of the pivot and front leveling screw the boom was given a period of exactly 15 seconds. When deflected 8 or 9 $\mathrm{mm}$. from its normal position, it took about 8 minutes before returning to rest. The instrument was kept going in this position from March 26 to November 9, 1902, when it was dismounted, removed to the large living hut, and erected on a masonry pillar (brick) of following dimensions:-

$$
\begin{array}{lllll}
\text { Depth sunk into ground } & \ldots & \ldots & \ldots & 12 \text { inches. } \\
\text { Height above ground } & \ldots & \ldots & \ldots & 3 \text { feet. } \\
\text { Breadth } \quad \ldots & \ldots & \ldots & \ldots & 2 \text { feet by } 2 \text { feet. }
\end{array}
$$

The instrument was so placed that the boom pointed S. - N. true; thus in an opposite direction to its former position. The period of the boom was made exactly fifteen seconds.

From January 29 until March 18, 1903, the seismograph was dismounted, the brick pillar being then employed for pendulum work, and was finally dismounted in December, 1903.

The seismograms procured over the two years show remarkably few tremors (136 during two years).

The following are the dates on which the largest tremors were observed:1902.

March 28. Prolonged tremors. Also recorded in New Zealand.

April 20. Ten minutes between preliminary tremors and maximum movement.

,21. Seventeen

May 26. Five ,

$\begin{array}{llll},, & , & , & , \\ , & , & ,\end{array}$




\section{PRELIMINARY REPORT ON THE PHYSICAL OBSERVATIONS CONDUCTED}

Aug. 10.

Sept. 22. Fifteen minutes between preliminary tremors and maximum movement.

Oct. 6. Tremor storm, nineteen hours' duration.

Dec. 25 .

1903.

April 11. Five minutes between preliminary tremors and maximum movement.

„29.

May 18.

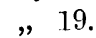

June 8.

July 9 .

Sept. 23.

, 25.

Oct. 8 .

„21. Twelve minutes between preliminary tremors and maximum movement.

,29.

Dec. 6.

The times of preliminary tremors, maxima, etc., are not here given, and in only a few cases have they been compared with the New Zealand records, such as that of September 22, 1902, where the movements on both seismograms seem practically identical, but of much smaller amplitude at the southern station. The seismic disturbances at Winter harbour were seldom large enough to appear on the magnetogram. Prolonged tremor storms, especially in October, were recorded, and well-defined pulsatory disturbances of a minute nature more frequently, especially in the winter, when a sudden fall in the outside temperature took place.

A large diurnal (?) movement of the horizontal pendulum is clearly perceptible. However, this wave movement may prove to be rather a monthly or seasonal one than diurnal. Sudden changes of barometric pressure are also clearly indicated.

It is within the bounds of possibility that manifestations of activity at a volcanic centre may be marked by a decline of the earth tremors of the district around, as though a safety-valve had been opened at that part of the Earth's surface. Certainly the fact of there being so few tremors is, perhaps, more interesting than if tremors had been large and frequent.

\section{Atmospheric Electricity.}

Observations of atmospheric electricity with the Kelvin portable electrometer were made during 1902 and 1903. During the winter months these observations were often very unpleasant to take on account of the small screws and bare parts of the small instrument, which could not be handled with mitted fingers. For a polar climate some larger instrument which does not necessitate the observer being frostbitten when using it in cold weather should be employed, or some form of self-recording electrometer.

The observations were taken on a stand about 4 feet above the ground, and away from any buildings, erections, etc. During the dark months observations were taken at 11 a.m. and 5 p.m. every day, excepting when high winds with low temperatures made it impossible. After the return of the sun observations were generally taken every two hours from 10 a.m. to 10 p.m. The direction of the wind, temperature, form of cloud, etc., was entered with the observation.

From 8 a.m. on November 22 to 8 a.m. on November 25, 1902, a series of hourly observations were carried out with the assistance of Mr. R. W. Skelton, R.N., chief engineer of the Discovery, and again in 1903 two hourly observations from noon on October 7 to noon on October 10. 
Besides the two series of three days, observations were occasionally taken on individual days throughout the twenty-four hours in both winter and summer.

The observations during the second year are not so complete as during the first, but are supplemented by observations taken at 15 feet above the ground, immediately after the observations at 4 feet, an insulated wire from the burning match at the top of the pole to the instrument being employed for the purpose.

None of the observations of atmospheric electricity have yet been reduced and tabulated, so nothing definitely can be said with regard to them.

The difference of potential is higher in summer than in winter, and the daily range is perceptible during the summer months, it being a maximum soon after midnight and a minimum about noon. In the winter months, if a range exists at all, it must be so small as to be most difficult to measure without some type of continuous self-recording instrument.

Whenever there was drifting snow in the air or fine ice-needles, the difference of potential was very large and variable, and in many cases the electrical strain would discharge the electrometer.

\section{Gravity Observations.}

Determinations of the constant of gravity in the southern hemisphere are singularly few. Those taken by various expeditions on the Falkland, Auckland, Kerguelen, South Shetland islands, etc., and at observatories such as Melbourne, Monte Video, etc., give evidence of an accordance of facts between the northern and southern hemispheres, but the data is far from being complete.

Until 1902 observations in a high southern latitude were utterly lacking.

The Struchrath pendulum apparatus of the expedition was acquired from the South Kensington Museum, and consists of three-quarter meter invariable pendulum swung on three separate agate planes, a dummy or temperature pendulum, an airtight case in which the pendulums are swung, flash apparatus, air-pump, and various other accessories.

It is not our purpose to describe the instrument in detail here, but to give some idea of the observations taken and the methods employed.

While at the Kew Observatory the air-tight case leaked very badly, the amount of leakage being on September 5, 1901, as much as $30 \mathrm{~mm}$. per hour at an initial pressure of $60 \mathrm{~mm}$. When at the Melbourne Observatory it was found quite impossible to reduce the pressure to anything like $60 \mathrm{~mm}$., and leakage was so great that both there and at Christchurch the pendulums had to be swung at atmospheric pressure. The whole weight of the extremely heary stand and case is supported by only three comparatively slender screws. The diameter of the case and rims being about 15 inches, it is evident that the unsupported metal parts between the screws are liable to "sag," and the contact between the rims is then no longer perfect. Mr. Skelton, by means of a surfacing plate, actually found this to be the case. He therefore re-surfaced both rims, which process considerably mitigated the leakage.

As the observations show, this leakage is of a uniform nature. The apparatus was set up in a small room, partitioned off from the large living hut, and the temperature within kept as uniform as possible by means of heating lamps, and was generally near zero centigrade. The pendulum stand was placed on the brick pillar used for the seismograph, and already described. The flash-box was erected on a small case filled with cement, and therefore very heavy, and which, in turn, rested on another larger case filled with heavy materials, and at a distance of about $285 \mathrm{cms}$. from the pendulum. A sidereal chronometer by Kulberg, with very small and regular rate, was used for noting the time of coincidences. When everything had been properly adjusted, the case was fitted over the pendulum, the 
pressure reduced to 50 or $60 \mathrm{~mm}$., and the observations commenced. The arrangement was as follows: twelve coincidences observed, six right and six left; then an interval of fifty coincidences allowed to pass, and twelve more coincidences observed. During this process four readings of pressure, temperature, and arc were obtained. The pendulum was then left to swing for two hours, and at the end of that time the same observation repeated. All three pendulums were swung in this manner; on the following day the case was taken off, the pendulums reversed on the agate planes, and the whole process repeated.

Thanks are due to Mr. R. W. Skelton for his valuable assistance throughout the gravity-work. He soon made himself competent in observing, and took independent sets on each occasion that the pendulums were swung.

The pendulums were swung at Melbourne and Christchurch before the departure of the expedition from New Zealand, and again at Christchurch on returning.

The following are the dates of observations made at Winter harbour :-

1902, July 31. Two complete sets with all three pendulums.

August 1.

1903, February 1. Ditto.

" 2.

, 6.

September 5. Ditto.

" 6.

The calculated acceleration for Winter harbour, found by the aid of Helmert's formula, $978.0(1+0.005310$ sin $2 \phi) \mathrm{cms}$., is $982.96 \mathrm{cms}$., and a determination from a set of observations taken at Winter harbour gives $982.83 \mathrm{cms}$. However, as some of the corrections have not been applied, this value can only be regarded as very roughly approximate.

From the geologist's report on the formation of the vicinity, a determination of a correction for density of the rocks can be made.

Before the paper, the President said: There is no occasion to introduce Mr. Bernacchi to you, because he has already given us a very interesting paper, and he is in a position which no other human being is in, on the face of the globe, in having passed three winters in the Antarctic Regions. On the last expedition he was physicist, and we have the evidence of his commander, Captain Scott, how very assiduous and careful he was in taking these observations, and under what very great difficulties they were carried out. I will now ask Mr. Bernacchi to read his paper.

Captain CREAK : I have listened with great pleasure to the lecturer and his plain, unvarnished account of the physical observations made by the Antarctic Expedition. Naturally, being chiefly interested in questions bearing upon the magnetic observations made during the years of sojourn in those quarters, I turn to them as the subject of my remarks. Perhaps many of us who live at home at ease, or who have only made observations in comparatively temperate climates, fail to make sufficient allowance for the severe conditions of the Antarctic climate when we criticize the work done by our intrepid explorers. It is easy to ask why was not this done, or why was not that done? and generally to find fault. This I do not propose to do, but I will consider shortly the good things the Discovery brought home. I notice that sea observations are excluded from this paper, but I may incidentally remark that a series of ship observations, which are possibly of great value, was taken after the pack-ice was entered. If wo look at the map, in 